\title{
INTENSITY OF TECHNOLOGY INTEGRATION IN PRIMARY SCHOOLS IN TANZANIA: THE CASE OF MERU DISTRICT
}

\author{
Dr. Thadei A. Kiwango \\ Lecturer, \\ Department of Informatics, \\ Institute of Accountancy Arusha, \\ P. O. Box 2798 Arusha, \\ Tanzania
}

Article DOI: $\underline{\text { https://doi.org/10.36713/epra3607 }}$

\begin{abstract}
This study measured the ability of the proposed out-of-school time (OST) learning model to intensify technology integration among primary school learners in Tanzania. The intensity of technology integration was determined by the extent the target users adopted educational technology. A quasi-experiment was deployed, involving experimental and control groups. The main participants of the study were 310 pupils in Meru District, Arusha Region. Additionally, parents and teachers of the experiment group participated as per the requirements of the proposed model. The category of teachers included five (5) mathematics teachers and three (3) head teachers in six primary day schools. The experiment ran for three months and data was recorded using digital Video Disks (DVDs), DVD Players, mobile phones, home works and list of perceived best practices. Pupils in the experimental group were treated under the proposed model while those in the control group were under traditional practices. The extent to which pupils used the technology was determined by the number of questions they attempted by using the technology, and the results compared between them. The t-test indicated a statistically significant improvement in the intensity of use of educational technology by the experiment group as compared to the control group $(t=$ 5.62, $N 1=167, N 2=143, S D 1=9.28, S D 2=12.8, p(0)<\alpha(0.05))$. These findings suggest the acceptance of the alternative hypothesis at $95 \%$ of confidence level and a conclusion that the proposed model improved the intensity of use of educational technology by OST learners in primary schools. This is suggestive of the need for the government to support projects related to integration of educational technology in order to trigger technology integration in Tanzania in general and in particular with regard to OST learning in primary schools. There is also need to investigate the ability of the proposed model to improve the intensity of use of educational technologies in other educational settings.
\end{abstract}

\section{INTRODUCTION}

Technology integration entails organization of instructional goals through the use of technology with the aim of making them coordinated and harmonious (Jolene, 1999). According to Ashleigh (2010) and David (2013), educational technology has also been found to be useful for application during out-of-school time learning for students in that it enhances the understanding of the concepts learnt at school, increases parental involvement, reducing costs, cultivating independent learning and building interest in school activities. Kimberly (2017) enumerates five major steps in technology integration, which subsume definition of the required technology; definition of the vision for technology integration and building a systematic plan for the integration. The other steps include seeking stakeholders' support and implementing and reviewing the effectiveness of the technology integration. Nearly similar steps have also been put forward by John (2013); and the list includes a number of steps that include planning, engagement of stakeholders, mobilization of resources as well as execution and management of technology integration plan. In practice, these steps can be collapsed into common major steps that include identification of the goal and vision of technology integration and 
development of an action plan in relation to budget, training needs and implementation strategies. The other steps are mobilization for stakeholders' engagements; implementation of the plan; and evaluation of the achievements of the objectives set forth.

The importance of a step-by-step planning and implementation of technology integration have been found to be imperative and prerequisite for success of technology integration especially in education and training in different parts of the world. For example, Jhurree et al. (2004) reports that the United Republic of Mauritius embarked on School IT Project that introduced ICT as among the subjects in primary schools from 2003. To make the initiative successful and effective, there was need to train teachers who would implement the project in schools. The deployed ICT teachers underwent initial training at the Mauritius Institute of Education and thereafter they were posted to primary schools countrywide. However, the teachers were later discouraged upon learning that the schools in which they were sent to implement the programme did not have the necessary ICT tools and infrastructure, including but not limited to computers, and this translated to disappointment to the whole nation state. In order to rescue the situation, the government decided to enhance the project through a phasedimplementation approach and consequently some 50 computer laboratories were made available in 50 primary schools yearly. The phase-implementation approach was thus found to be feasible and realistic for realization of the intended goals. This is suggestive of the fact successful integration of technology in the context of education and training depends heavily on the degree to which the implementing agency and project initiators systematically follow pertinent principles and procedures as a requirement.

In the context of Tanzania, the rate of adoption of ICTs was initially constrained by the decision of the government to sanction the importation of computers in 1974. The situation, which greatly limited importation of computers to the country, seriously and negatively impacted on the use of computers, the situation which continued to the demise of the East African Community (EAC) in 1977. The collapse of EAC consequently necessitated the government of Tanzania to adopt the already computerized systems which were operative during the EAC, and afterwards the country adopted trade liberalization policy in 1980s (Mgaya, 1994). From the time onwards, the political will has been in favour of education as evidenced by approval of relevant policies which encourage the use of technology in education provision in the country, including the ICT Policy for Basic Education (URT, 2014).
Following the structural adjustments that witnessed trade liberalization in the $1980 \mathrm{~s}$, some projects which were directed adoption and use of ICTs in the education system have punctuated the scene. For example, the government of Tanzania showed the way by implementing ICT projects in Teachers' Colleges and secondary schools along with incorporation of computer as an independent course of study in the school curriculum. Other initiatives include eSchool Forum, Education Management Information System (EMIS), Tanzania Education Services Website, Computer Procurement and Refurbishment for Schools and Barclays Computer for Schools (Nyirenda, 2013).

The introduction of ICT in secondary school was intended to enhance the use of ICT in all secondary schools by 2015. Likewise, the Computer Procurement and Refurbishment for Schools was a programme that sought to avail used computers to schools after refurbishment before on ward supply to computer laboratories in mostly secondary schools. Moreover, the Tanzania Education Services Web site and EMIS were intended to manage and disseminate educational information whereas Barclays Computer for Schools Project had the intention of availing about 10,000 computers to approximately 500 schools across the country.

Apart from the endeavours championed by the government, local institutions and practitioners have never remained passive. Cases in point include, but not limited to, the Ubongo Kids (Communication Initiative Network, 2014). Indeed, the institution has joined the scene invested in the efforts directed to ICT integration particularly for OST learning. In the views of the Communication Initiative Network (2014), Ubongo Kids is among prominent institutions which produce series of educative cartoons in Tanzania; and it has been very instrumental in supporting children in learning science mathematics through songs, local stories and funs. Ubongo Kids has also successfully offered supplement programmes that have enhanced inclass learning especially with regard to coverage of difficult topics to ensure smooth understanding for pupils in primary schools.

Despite of different initiatives by governmental and non-governmental institutions to cherish integration of technology in education, it has been demonstrated in different studies that actual adoption and use of educational technology in Tanzania particularly as far as OST is concerned, still have a long way to go (Adomi and Kpangban, 2010; Swart and Wachira, 2010). According to Ashleigh (2010) and Surry and Ely (2001), one of the explanations behind the observed inadequacy is lack of strategies and models that entice learners to adopt and use technology 
for their educational pursuits. This paper follows a Thesis developed by Kiwango in 2018, which was essentially for award of a doctoral degree in informatics. The Thesis was an attempt to model the hastening of technology integration for OST learning for primary school pupils in Tanzania. The focus of this paper is to evaluate the extent the model was successful in improving the intensity of technology integration.

\section{METHODOLOGY}

The study used a quasi-experiment comprising experimental and control groups where the actual responded that were captured in the same were mainly 310 primary school pupils (167 and 143 from experimental and control groups respectively) drawn from six (6) day primary schools in Meru District, Arusha Region were involved. Additionally, the parents (127) together with teachers (5 mathematics teachers and 3 head teachers) of experimental group were involved as per the requirements of the proposed model to support the pupils in using the educational technology.

Although technologies like radio were also considered for the experiment, the use of DVDs was thought to be most relevant and could better suit the purpose of the experiment. For instance, DVDs could be used offline and conveniently enable pupils to access and us the content at their own convenience. But this technology also requires reliable source of power, and the Tanzania Electricity Supply Company (TANESCO) served as the main power supplier in Meru District. As a result, the sampling of schools and hence respective families considered the availability of power. However, schools which were located far from the Moshi-Arusha highway had limited access to electricity. For that case, the schools located in close proximity with the highway were most preferable. On the other hand, The target was to select schools of which 30 pupils from class five or six had access to televisions at home; and thus, they could use the supplied technological devices such as DVDs during out of school time.

It was also necessary to consider that the experiment would be conducted to schools and families of which their average socio-economic and cultural conditions represent the Tanzanian majority. It was advised by the District Chief School Quality Assurance Officer that; public Kiswahili medium schools were found to meet this requirement as compared to private English medium schools. It was explained by the District Education Office; that private schools, in which English is the medium of instruction, tend to be too expensive for most families to find places for their children. Likewise, the involvement of pupils from public schools demanded the use of Kiswahili in designing the content of the technology. The content was made more relevant by adopting the syllabus developed by the National Examination Council of Tanzanian (NECTA).

In the course of selecting the schools to be involved in the study, the number of Kiswahili-medium day schools was obtained from the District Education Office. The first 18 schools which were located closer to Moshi- Arusha highway were picked for the intended purpose. Then, class six and five pupils were asked to state whether their families own television. The leading six schools with more pupils with television at home were selected. Furthermore, the number of pupils with television at home were higher in class six than class five and hence class six pupils were selected.

In addition to having access to televisions, the degree of supervisory support extended to pupils at home during OST learning was also an important consideration. Thus, pupil were asked to rank the availability of parental supervisory supports at their homes. The ultimate goal was to standardise the supervisory supports among the selected schools. At the bottom line, 12 schools out of 18 had about 30 pupils who had access to television at home. Then, the 12 schools were arranged on the basis of OST learning supervisory support at home. The list was subsequently split into three groups each comprising four (4) schools where two schools at the mid of each category were selected making a sum of 6 schools. One of the selected schools was arbitrarily considered as experimental group and the other as control group. The aim was to see the extent the resultant model would speed up the intensity in the use of the provided educational technology.

The experiment ran for three (3) months during which the experimental group was subjected to the proposed model while the control group maintained traditional practices. DVDs packaged with instructional content based on class six NECTA syllabus were given to pupils in the two groups. To ease the use of the given technology, a list of perceived best practices on the use of the target technology was also availed to the pupils, parents and teachers of only the experimental group. The included best practices included the roles of pupils, parents and teachers in enabling efficient use of the given technology, and these features distinguished the two groups involved in the experiment.

The experimented questions and corresponding marking schedules were developed and evaluated by an independent panel consisting of two mathematics teachers from a school different from the two involved in the experiment. The examining panel was availed 
with the DVDs for them to familiarize with the content and presentation of the same before carrying out their tasks. The DVDs comprised questions for different topics designed in a way that required a learner to view the technology content in order to respond to the tasks accordingly. In this context, the number of questions answered by a pupil was reasonably considered to relate to the intensity the pupil used the technology. After the tasks, the answer booklets were taken to the subject teachers for marking and rating, based on the marking schedule determined by the examining panel. The number of questions responded by each pupil was recorded as a base to determine the intensity of technology use.

Data was analyzed with the aid of the Statistical Package for Social Sciences (SPSS), and the resultant quantitative data was presented in percentages, mean and t-test and the results were compared across the two involved groups. T-test was deployed to check for any statistically significant improvement in the intensity of using the educational technology between the two groups.

\section{FINDINGS}

A total of 167 pupils constituted the experimental and another143 represented the control, where 165 questions were to be answered by the participating pupils. On one hand, the sum of questions responded by the experimental group was 11,022; making the mean of 66 (i.e. 11022/167) out of 165 questions. On the other hand, a sum of 4,004 questions with a mean of 28 (i.e. 4004/143) out of 165 questions were answered by pupils in control group. Based on the statistics, the mean of the experimental group (66) was twice as much as that of the control group (28). In terms of percentage, the mean of the experimental group accounts for $40 \%$ of all the 165 questions as compared to $16 \%$ of the control group. Furthermore, the t-test substantiated that the intensity of the use of the target educational technology varied significantly between the two groups such that: $\mathrm{t}=5.62, \mathrm{~N} 1=167$, $\mathrm{N} 2=143, \mathrm{SD} 1=9.28, \mathrm{SD} 2=12.8, \mathrm{p}(0)<\mathrm{\alpha}(0.05)$.

The results are indicative of the existence of substantial difference in the intensity of technology use in favour of the experimental group, demanding the acceptance of the alternative hypothesis at 95\% confidence. On the basis of the results, therefore, deployment of the proposed model for integration of OST technology is likely to enhance the intensity of use of educational technology especially among primary school pupils during OST learning.

\section{DISCUSSION}

The analysis of the findings in this paper reveals that although the use of educational technology enhances the intensity of use, the intensity of use of similar technologies among primary school pupils is not adequate. This trend is somewhat similar to the situation in-school situations because the two environments interact and influence one another to a great extent. Several studies have found the low usage of educational technology in Tanzania. For instance, Nihuka and Peter (2014) which found that only 11.4\% of Tanzanian primary school pupils could use simple computer programmes. Moreover, some pupils less than $21.7 \%$ could use the internet to send and read emails. It was claimed that low ICT literacy could be explained by lacking accessibility of modern technological devices especially computers and smart phones. It was shown in the study that only $11.3 \%$ of primary school pupils had access to computers. Similarly, only $1.9 \%$ of pupils had access to the internet.

Kiwango (2020), established that the use of computers was still inadequate because of limited awareness, accessibility and the ability to use technological devices among pupils in Tanzanian primary schools. Specifically, the study unveiled that only $18.8 \%$ of primary school pupils in Tanzania knew the usefulness of computers while only $9.6 \%$ of pupils lived in families which owned computers. Given the small number of pupils who had access to computers, the implication is that most students were not even likely to learn how to use computers. It is also shown in the same study that only $16.6 \%$ of primary school pupils in Tanzania could use computers without the support of an expert. Therefore, the lacking awareness, accessibility and ability to use computers is likely to translate in low intensity of use of educational technology by pupils for OST learning.

Other previous studies have also found low intensity in the use of educational technology among school children. Among the factors attributed to the situation include low intensity of use of educational technology in schools, which is likely to have also affected its use in OST environments.

On the other hand, the low intensity in educational technology usage is attributed by the low intensity of educational technology use in schools, which may have probably adversely affected its use in OST environments. The UNESCO (2009) observes that the proportion of teaching staff adapting their skills to an ICT-enabled instruction model is small in developing countries and the nature and intensity of ICT use in schools is very low. Nevertheless, studies have revealed that primary schools' pupils are capable 
of using the non-educational technology like television in OST contexts. For instance, Kiwango (2018) found that more than $50 \%$ of pupils in primary schools could use televisions at home; which implies that educational technology can also be exploited successfully if it is made available. However, availability of technology should also be accompanied by due guidance on the use of technology, and this is a necessary condition for enhanced intensity of use of technology for improved educational output. According to Kiwango (2018), a scientific model is necessary to entice the educational technology usage by primary school pupils in OST contexts.

\section{CONCLUSION AND RECOMMENDATIONS}

It has been demonstrated in this paper that the intensity of use of educational technology in primary schools in the context of OST learning can be enhanced and guided by the use of a scientific model. It can be observed that the low intensity of use of educational technology in schools could have resulted from lack of awareness, accessibility and ability to use educational technology. Based on these observations, it is proposed that educational stakeholders, including parents, teachers, the government and the community as a whole should work together for the purpose of enhancing the intensity of using technology both in school and during out-of-school learning. One of the advantages expected to accrue from this partnership is that the persistent shortage of teaching and learning resources can be checked to a great extent leading subsequently to improved academic achievements among pupils. Some of the areas on which the partnership could focus include raising the awareness and improving accessibility of the available technological resources for possible integration into the education system for use both during school and out-ofschool learning. Further studies that explore the interventions to raise the awareness and accessibility of educational technology resources and successfully integrated in educational systems in both school and out-of-school contexts are useful to improve the intensity of educational technology integration by OST primary school pupils in Tanzania.

\section{REFERENCES}

1. Adomi, E. \&Kpangban, E. (2010), Application of ICT in Nigerian Secondary Schools, Delta State University, Asaba.

2. Ashleigh, C. (2010), "Incorporating Technology in out-of-school time programs: Benefits, Challenges and Strategies", [https://www.childtrends.org/wpontent/uploads/2010/03/child_trends- 2010_03_01_rb_technologyost.pdf], site visited on $12 / 01 / 2015$.

3. Ayoub K. et al. (2015), ICT Use in Science and Mathematics Teacher Education in Tanzania:

4. Developing Technological Pedagogical Content Knowledge, Australasian Journal of Educational Technology, Vol 31(4)

5. Communication Initiative Network (2014), "Ubongo Kids Cartoon Series", [https://www.comminit.com/africa], site visited on 4/5/2017.

6. David, A. (2013), "iPads in the Classroom: Embedding Technology in the Primary Curriculum",

7. [https://www.theguardian.com/teachernetwork/teacher-blog/2013/mar/06/ipad-ipodtechnology-primary-curriculum], site visited on 13/03/2015.

8. George Lucas Educational Foundation (2007), "What Is Successful Technology Integration?", [https://www.edutopia.org/technology-integrationguide-description], site visited on 18/6/2017.

9. Jhurree, V. et al., (2004), "Student Teachers' Perceptions of Pedagogical Choices in a PreService ICT Teacher Education Course": MIE Journal of Education, Vol. No. 3, 79-96.

10. John, D. (2013), "Diffusion of Innovations Relating to Educational Technology", [httpss://meltingiceburgs.wordpress.com/2013/08/1 9/diffusion-of-innovations-relating-to-educationaltechnology], site visited on 20/3/2017.

11. Khasawneh, M. et al. (2012), "A Model for Adoption of ICT in Jordanian Higher Education Institutions".

[https://www.ibimapublishing.com/journals/jelhe/2 012/.../877178.pdf], site visited on 27/03/2015.

12. Kimberly, B. (2017), "The top 5 Steps for Successful Technology Integration”, [https://www.dentaleconomics.com/articles/print/vo lume-107/issue-4/practice/the-top-5-steps-forsuccessful-technology-integration.html], visited on 4/4/2017.

13. Kiwango, T. A. (2018), A model to hasten technology integration for out-of-school time primary school learning (Doctoral thesis). Tanzania: The University of Dodoma.

14. Kiwango (2020), "Accessibility, awareness and ability to use computers by primary school pupils" EPRA International Journal of Research and Development, Vol. 5, No. 5, 552-557.

15. Mgaya, K. (1994), "Development of Information Technology in Tanzania”,

16. [https://www.tanzaniagateway.org], site visited on 22/05/2015.

17. Nyirenda, M. (2013), "Planning for ICT Literacy in Public Schools in Tanzania", [https://www.ippmedia.com/frontend/?l=62206], site visited on 16/03/2015.

18. Safia, B., et al. (2004), "How a Web-based Course Facilitates Acquisition of English for academic 
purposes”. Language Learning \& Technology, Vol. 8, No.2, 33-49.

19. Swart P. and Wachira E. (2010), Tanzania: ICT in Education Situational Analysis,

20. [https://www.gesci.org/assets/files/Knowledge\%20 Centre/Situational\%20Analysis_Tanzania.pdf], site visited on 16/03/2015.

21. The International Society for Technology in Education (2004), "National Education Technology Standards (NETS) for teachers, students, and administrators", [https://online.tarleton.edu], site visited on 13/5/2017.

22. UNESCO (2009), Guide to Measuring Communication Technologies (ICT) in Education. UNESCO Institute for Statistics. Montreal, Canada.

23. Usluel, $Y$ et al. (2008), "A Structural Equation Model for ICT Usage in Higher Education", Educational Technology \& Society, Vol. 11, No. 2, 262-273.

24. URT (2014), "ICT Policy for Basic Education", [moe.go.tz], site. 